\title{
Impact of National HIV and AIDS Communication Campaigns in South Africa to Reduce HIV Risk Behaviour
}

\author{
Karl Peltzer, ${ }^{1,2}$ Warren Parker, ${ }^{3}$ Musawenkosi Mabaso, ${ }^{1}$ Elias Makonko, ${ }^{1}$ \\ Khangelani Zuma, ${ }^{1}$ and Shandir Ramlagan ${ }^{1}$ \\ ${ }^{1}$ HIV/AIDS, STIs and TB (HAST), Human Sciences Research Council, Private Bag X41, Pretoria 0001, South Africa \\ ${ }^{2}$ Department of Psychology, University of Limpopo, Turfloop Campus, Private Bag X1106, Sovenga 0727, South Africa \\ ${ }^{3}$ Centre for AIDS Development, Research and Evaluation, P.O. Box 30829, Braamfontein 2017, South Africa
}

Correspondence should be addressed to Karl Peltzer, kpeltzer@hsrc.ac.za

Received 15 September 2012; Accepted 11 October 2012

Academic Editors: K. F. Harrington, P. A. Mardh, and B. Stanton

Copyright () 2012 Karl Peltzer et al. This is an open access article distributed under the Creative Commons Attribution License, which permits unrestricted use, distribution, and reproduction in any medium, provided the original work is properly cited.

\begin{abstract}
In South Africa social and behavioural communication interventions are a critical component of HIV/AIDS prevention, and numerous communication campaigns have been implemented intensively across the country through government initiatives and nongovernmental organisations over the past decade. The aim of this paper is to assess the reach of HIV and AIDS communication campaigns in conjunction with contributions to knowledge, attitudes, and HIV risk behaviours in the general population in South Africa. The sample included in this nationally representative cross-sectional survey was 13234 people aged 15-55 years. Overall, the study found that there was high exposure to 18 different HIV communication programmes (median 6 programmes and 14 programmes more than $30 \%$ ) across different age groups. Most programmes were more often seen or heard by young people aged between 15 and 24 years. In multivariate analysis, greater exposure to HIV mass communication programmes was associated with greater HIV knowledge, condom use at last sex, having tested for HIV in the past 12 months, and less stigmatizing attitude toward PLWHA.
\end{abstract}

\section{Introduction}

Population-wide mass media can use the combination of television, radio and print. This includes television and radio, episodes as well as inserts in key newspapers during each year of intervention, and the campaigns are repeated annually. Bertrand et al. [1] examined the effectiveness of 24 mass media interventions on changing HIV-related knowledge, attitudes- and behaviours in low- and middleincome countries. The most frequently reported outcomes were condom use (17 studies) and knowledge of modes of HIV transmission (15), followed by reduction in highrisk sexual behaviour (8), perceived risk of contracting HIV/AIDS (6), interpersonal communication about AIDS or condom use (6), self-efficacy to negotiate condom use (4), and abstaining from sexual relations (3). The studies yielded mixed results, and where statistically significant, the effect size was small to moderate (in some cases as low as $1-2 \%$ point increase). On two of the seven outcomes, at least half of the studies did show a positive impact of the mass media in the improvement of knowledge of HIV transmission and reduction of high-risk sexual behaviour [1]. In a more recent review, Noar et al. [2] evaluated 34 distinct HIV/AIDS campaign efforts conducted in 23 countries and found among the $30 \%$ of studies with stronger outcome evaluation designs, that the vast majority of the well-controlled studies demonstrated effects on knowledge (increased AIDS knowledge), behaviour (increased condom use; reductions in numbers of sexual partners; were more likely to get tested for HIV), or behavioural intentions (increased condom use intentions). In addition, several studies [3-5] found that exposure to HIV-related communication on the media was significantly related to less stigmatizing attitude toward people living with HIV and AIDS (PLWHA).

In South Africa social and behavioral communication interventions are a critical component of HIV/AIDS prevention [6]. Numerous communication campaigns have been implemented intensively across the country through 
TABLE 1: Percentage of people accessing various media channels.

\begin{tabular}{|c|c|c|c|c|}
\hline \multirow{2}{*}{ Media channels } & \multicolumn{4}{|c|}{ Frequency of accessing various media channels } \\
\hline & Never & Once a week & 2-6 times a week & Every day of the week \\
\hline Listen to radio & 16.4 & 9.9 & 16.5 & 57.1 \\
\hline Watch television & 18.3 & 5.5 & 10.3 & 65.9 \\
\hline Read a magazine & 39.3 & 29.0 & 18.8 & 12.9 \\
\hline Read a newspaper & 33.1 & 26.6 & 18.0 & 22.4 \\
\hline Use the internet & 82.3 & 4.9 & 4.6 & 8.2 \\
\hline
\end{tabular}

government initiatives and nongovernmental organisations over the past decade [6-8]. The purpose is to help combat the spread of HIV and AIDS by improving knowledge about modes of transmission, risk perceptions, changing sexual behaviours, questioning potential harmful social norms, and promoting resources and services that support prevention $[6,9]$.

Campaigns utilise radio, television, and other outlets to address prevention of HIV/AIDS by conveying messages through interpersonal, community, and national channels $[7,8]$. Four major national-level HIV and AIDS communication programmes using mass media and other communication channels include Khomani, meaning "caring together;" LoveLife, which focuses mainly on teenagers, Soul City and Soul Buddyz which address adults and children, respectively, and the 46664 campaign which aims to promote HIV prevention through a series of events and activities linked to the ethos and values of Nelson Mandela. This latter campaign is conducted nationally, but also extends globally $[6,8]$.

National HIV/AIDS communication surveys demonstrated impacts in the improvement of knowledge and awareness and have illustrated outcomes related to HIV prevention [7-9]. An evaluation of Soul City in South Africa illustrates the mediation of community change as a product of communication programming [10]. In a national communication survey in 2009, Johnson et al. [6] found that HIV communication programmes as a whole brought about positive changes in condom use and HIV testing but did not impact on reduction of multiple sexual partners. In an evaluation of a youth programme (loveLife) (combining multimedia and community outreach and support programmes) in South Africa, Pettifor et al. [11] found that the participation in loveLife reduced chances of being infected with HIV, and youth were more likely to report condom use at last sex and used condoms more consistently.

The aim of this paper is to assess the reach of these communication campaigns in conjunction with contributions to knowledge, attitudes, and HIV risk behaviours in the general population in South Africa.

\section{Methods}

2.1. Sample and Procedure. The survey targeted all persons over 2 years of age living in South Africa and residing in homes (i.e., excluding individuals living in educational institutions, old-age homes, hospitals, and uniformed service barracks but including those living in hostels). A multistage cluster stratified sample stratified by province, settlement geography (geotype), and predominant population group in each area was used. A systematic sample of 15 households was drawn from each of 1000 census enumeration areas (EAs). In each household, one person was randomly selected in each of the four mutually exclusive age groups (under 2 years; $2-14$ years; $15-24$ years; $25+$ years). Sociodemographic and behavioural information was collected with questionnaires administered by trained field workers (more details on the methodology are described by Shisana et al., [8]). The age group selected for analysis in this paper was 13234 people aged 15-55 years. This age range was chosen because of greater HIV risk.

Ethical approval for conducting the study was obtained from the Human Sciences Research Council's Ethics Committee (Application number REC5/24/04). Informed consent was obtained for agreeing to participate in the interview. Registered professional nurses were trained to conduct interviews.

2.2. Measure. A structured questionnaire was used to determine the reach of national mass media communication campaigns that promote HIV/AIDS education in South Africa. Respondents were asked questions related to mass media reach as well as their knowledge of campaigns and perceptions of HIV/AIDS communication in general. The sections of the questionnaire analysed here included access to media channels and exposure to 18 different HIV mass communication programmes in the past 12 months in South Africa. Impact of the HIV mass communication programmes was measured in terms of HIV knowledge (16 items, Cronbach's alpha of 0.72), sexual risk behaviour (multiple sexual partners, condom use, HIV testing), and HIV stigma attitudes (5 items, Cronbach's alpha of 0.54).

\section{Data Analysis}

To create a joint index of HIV mass communication exposure, each programme was coded $0 / 1$ for recall and then summed to create scale from 0 to 18 . By taking the median of 6 as a cut-off point, this scale was dichotomised as low or high exposure, and it was further grouped into three groups of $1=0-3$ exposures, $4-8$, and 9 or more exposures to mass communication programmes. Other dependent variables included HIV knowledge, which was dichotomised into $1=$ 14-18 correct responses and $0=0-13$ correct responses and 
TABLE 2: HIV mass media communication exposure in the past 12 months by age group expressed as percentages.

\begin{tabular}{|c|c|c|c|c|}
\hline Mass media programme & $\begin{array}{c}\text { Age } 15-24 \\
N=5344 \\
\%\end{array}$ & $\begin{array}{c}\text { Age } 25-35 \\
N=2644 \\
\%\end{array}$ & $\begin{array}{c}\text { Age } 36-55 \\
N=5246 \\
\%\end{array}$ & $\begin{array}{c}\text { Age } 15-55 \\
N=13234 \\
N(\%)\end{array}$ \\
\hline (1) Watched Soul City on television & 62.0 & 58.9 & 49.5 & $5718(56.6)$ \\
\hline (2) Listened to Soul City on the radio & 36.6 & 37.1 & 34.7 & $3374(36.0)$ \\
\hline (3) Watched Beat It-Siyanqoba on television & 26.7 & 27.6 & 20.4 & $2264(24.7)$ \\
\hline (4) Watched Masupatsela on television & 12.2 & 13.0 & 10.5 & $1122(11.8)$ \\
\hline (5) Listened to a talk show about AIDS on television & 56.8 & 57.9 & 52.0 & $6015(55.4)$ \\
\hline (6) Listened to a talk show about AIDS on the radio & 48.5 & 50.3 & 47.6 & $4891(48.7)$ \\
\hline (7) Seen a loveLife advert on television & 66.5 & 60.4 & 49.0 & $6381(58.4)$ \\
\hline (8) Heard a loveLife advert on radio & 51.9 & 52.3 & 40.8 & $4828(48.0)$ \\
\hline (9) Seen a loveLife billboard & 61.2 & 58.9 & 46.8 & $5892(55.3)$ \\
\hline (10) Read UnCut (loveLife youth magazine) & 32.7 & 21.2 & 14.5 & $2486(22.7)$ \\
\hline (11) Seen a Khomanani advert on television & 59.3 & 56.4 & 48.0 & $5455(54.4)$ \\
\hline (12) Heard a Khomanani advert on radio & 44.5 & 45.1 & 38.7 & $4026(42.5)$ \\
\hline (13) Heard about New Start HIV testing centres & 21.2 & 23.7 & 20.2 & $2515(21.6)$ \\
\hline (14) Watched Soul Buddyz on television & 60.6 & 51.8 & 39.4 & $5338(50.3)$ \\
\hline (15) Read Soul City Booklet & 44.9 & 34.4 & 25.0 & $3638(34.5)$ \\
\hline (16) Watched Buddyz on the move on television & 44.7 & 35.8 & 24.4 & $3493(34.7)$ \\
\hline (17) Heard about the 46664 & 58.8 & 58.8 & 52.1 & $6279(56.4)$ \\
\hline (18) Heard about the play "Khululeka/It's in our hands." & 26.1 & 30.0 & 24.9 & $2561(26.8)$ \\
\hline
\end{tabular}

TABLE 3: Association of demographic characteristics and overall exposure to HIV communication campaigns $(N=13234)$.

\begin{tabular}{|c|c|c|c|}
\hline Demographic characteristics & $N(\%)$ & $\operatorname{AOR}(95 \% \mathrm{CI})$ & $P$ value* \\
\hline \multicolumn{4}{|l|}{ Age } \\
\hline $15-24$ & $5344(35.1)$ & 1.00 & \\
\hline $26-35$ & $2644(29.3)$ & $0.77(0.65-0.90)$ & 0.001 \\
\hline $36-55$ & $5246(35.6)$ & $0.71(0.61-0.82)$ & $<0.001$ \\
\hline \multicolumn{4}{|l|}{ Sex } \\
\hline Women & $7518(52.0)$ & 1.00 & \\
\hline Men & $5716(48.0)$ & $1.05(0.92-1.20)$ & 0.481 \\
\hline \multicolumn{4}{|l|}{ Education } \\
\hline Grade $0-7$ & $2266(19.8)$ & 1.00 & \\
\hline Grade 8-11 & $5288(42.8)$ & $3.14(2.61-3.78)$ & $<0.001$ \\
\hline Grade 12 or more & $4775(37.4)$ & $5.34(4.36-6.54)$ & $<0.001$ \\
\hline \multicolumn{4}{|l|}{ Geolocality } \\
\hline Urban formal & $8290(54.2)$ & 1.00 & \\
\hline Urban informal & $1577(10.2)$ & $0.55(0.42-0.73)$ & $<0.001$ \\
\hline Rural & $3367(35.6)$ & $0.34(0.27-0.42)$ & $<0.001$ \\
\hline \multicolumn{4}{|l|}{ Population group } \\
\hline White & $1509(9.2)$ & 1.00 & \\
\hline Black African & $7750(78.5)$ & $0.10(0.07-0.13)$ & $<0.001$ \\
\hline Coloured & $2512(9.6)$ & $0.70(0.55-0.89)$ & 0.003 \\
\hline Indian or Asian & $1428(2.6)$ & $0.32(0.19-0.54)$ & $<0.001$ \\
\hline
\end{tabular}

Adjusted odds ratio: AOR. * Significance tested using logistic regression at $P$ value $<0.05$.

HIV/AIDS stigma, which was dichotomised into $1=2-5$ scores and $0=0-1$ scores. Accounting for complex sampling design, a weighted analysis of the outcome of interest was carried out for the main reporting domains. Weighted data were analyzed using STATA 10.0 software. STATA suite of survey commands was used to obtain estimates with $95 \%$ confidence intervals that took into account the survey design. Adjusted odds ratios (ORs) are reported to indicate the strength and direction of association. A $P$ value less than $5 \%$ is used to indicate statistical significance. 
TABLE 4: Association between HIV communication campaigns and outcome variables.

\begin{tabular}{|c|c|c|c|c|c|}
\hline \multirow[t]{2}{*}{ Outcome variables } & $\begin{array}{l}\text { HIV knowledge } \\
\quad(63.1 \%)\end{array}$ & $\begin{array}{l}\text { Condom use at last } \\
\operatorname{sex}(61.2 \%)\end{array}$ & $\begin{array}{l}\text { Two or more sexual } \\
\text { partner in the past } 12 \\
\text { months }(9.8 \%)\end{array}$ & $\begin{array}{l}\text { Tested for HIV in the } \\
\text { past } 12 \text { months } \\
(24.7 \%)\end{array}$ & $\begin{array}{c}\text { HIV stigma attitudes } \\
(32.8 \%)\end{array}$ \\
\hline & $\operatorname{AOR}(95 \% \mathrm{CI})^{1}$ & $\operatorname{AOR}(95 \% \mathrm{CI})^{1}$ & $\operatorname{AOR}(95 \% \mathrm{CI})^{1}$ & $\operatorname{AOR}(95 \% \mathrm{CI})^{1}$ & $\operatorname{AOR}(95 \% \mathrm{CI})^{1}$ \\
\hline \multicolumn{6}{|l|}{ Age } \\
\hline $15-24$ & 1.00 & 1.00 & 1.00 & 1.00 & 1.00 \\
\hline $26-35$ & $1.17(0.98-1.40)$ & $0.39(0.31-0.48)^{* * *}$ & $0.59(0.43-0.81)^{* * *}$ & $1.75(1.47-2.09)^{* * *}$ & $0.95(0.80-1.14)$ \\
\hline $36-55$ & $1.19(1.02-1.39)^{*}$ & $0.34(0.27-0.43)^{* * *}$ & $0.28(0.20-0.39)^{* * *}$ & $1.38(1.16-1.64)^{* * *}$ & $1.03(0.87-1.22)$ \\
\hline \multicolumn{6}{|l|}{ Sex } \\
\hline Women & 1.00 & 1.00 & 1.00 & 1.00 & 1.00 \\
\hline Men & $0.80(0.70-0.92)^{* *}$ & $1.28(1.07-1.53)^{* *}$ & $5.27(4.62-8.50)^{* * *}$ & $0.64(0.55-0.74)^{* * *}$ & $1.27(1.12-1.44)^{* * *}$ \\
\hline \multicolumn{6}{|l|}{ Education } \\
\hline Grade $0-7$ & 1.00 & 1.00 & 1.00 & 1.00 & 1.00 \\
\hline Grade 8-11 & $1.63(1.38-1.94)^{* * *}$ & $0.99(0.75-1.31)$ & $1.10(0.73-1.67)$ & $0.95(0.77-1.16)$ & $0.67(0.56-0.80)^{* * *}$ \\
\hline Grade 12 or more & $3.29(2.65-4.08)^{* * *}$ & $0.82(0.61-1.11)$ & $1.04(0.69-1.57)$ & $1.32(1.05-1.67)^{*}$ & $0.44(0.36-0.54)^{* * *}$ \\
\hline \multicolumn{6}{|l|}{ Geolocality } \\
\hline Urban formal & 1.00 & 1.00 & 1.00 & 1.00 & 1.00 \\
\hline Urban informal & $0.99(0.81-1.21)$ & $0.89(0.66-1.18)$ & $0.75(0.49-1.16)$ & $0.99(0.79-1.25)$ & $0.92(0.71-1.20)$ \\
\hline Rural & $0.86(0.72-1.02)$ & $0.92(0.73-1.16)$ & $0.88(0.63-1.23)$ & $0.96(0.79-1.16)$ & $1.65(1.35-2.01)^{* * *}$ \\
\hline \multicolumn{6}{|l|}{ Population group } \\
\hline Black African & 1.00 & 1.00 & 1.00 & 1.00 & 1.00 \\
\hline White & $2.08(1.53-2.84)^{* * *}$ & $0.22(0.16-0.30)^{* * *}$ & $0.58(0.34-1.00)^{*}$ & $0.85(0.63-1.15)$ & $1.58(1.22-2.05)^{* * *}$ \\
\hline Coloured & $0.76(0.64-0.90)^{* *}$ & $0.28(0.22-0.36)^{* * *}$ & $0.77(0.52-1.15)$ & $0.82(0.66-1.01)$ & $2.41(1.99-2.93)^{* * *}$ \\
\hline Indian or Asian & $1.25(0.78-2.00)$ & $0.22(0.15-0.34)^{* * *}$ & $0.10(0.05-0.20)^{* * *}$ & $0.52(0.38-0.71)^{* * *}$ & $2.19(1.53-3.14)^{* * *}$ \\
\hline \multicolumn{6}{|l|}{$\begin{array}{l}\text { HIV communication } \\
\text { Campaigns }\end{array}$} \\
\hline $0-3$ & 1.00 & 1.00 & 1.00 & 1.00 & 1.00 \\
\hline $4-8$ & $1.50(1.26-1.79)^{* * *}$ & $1.30(1.03-1.64)^{*}$ & $1.00(0.70-1.41)$ & $1.03(0.86-1.24)$ & $0.71(0.60-0.84)^{* * *}$ \\
\hline 9 or more & $1.99(1.67-2.36)^{* * *}$ & $1.28(1.00-1.62)^{*}$ & $0.93(0.65-1.33)$ & $1.45(1.19-1.78)^{* * *}$ & $0.41(0.34-0.49)^{* * *}$ \\
\hline
\end{tabular}

Adjusted odds ratio: AOR. ${ }^{1}$ Adjusted by media access (radio, TV, newspaper, magazine, and Internet). Significance tested using logistic regression at $* * * P<$ $0.001 ;{ }^{* *} P<0.01 ;{ }^{*} P<0.05$.

\section{Results}

4.1. Access to Media. Radio and television are the most popular mass media consumed by people in South Africa, with $81.7 \%$ of people watching TV and $83.6 \%$ listening to the radio. While $66.9 \%$ and $60.7 \%$ of people reported reading a newspaper and a magazine, respectively, only $22.4 \%$ and $12.9 \%$ reported reading a newspaper and a magazine, respectively, every day. The internet was the least accessed channel, with $17.7 \%$ of the population accessing it (see Table 1).

4.2. Exposure to HIV Mass Communication Programmes. Exposure is defined as have heard or seen at least one of any HIV mass communication programme such as billboard, radio, $\mathrm{TV}$, or other components in the past 12 months prior to the survey interview. Overall, a high exposure to 18 different HIV communication programmes (median 6 programmes and 14 more than
$30 \%$ ) across different age groups was found. Most programmes were more often seen or heard by youth (15-24 years), and this is in addition to programmes specifically designed for youth such as loveLife and Soul Buddyz (see Table 2).

The median exposure to HIV mass communication among participants was 6 programmes, IQR 3-9. In the multivariate analysis, younger age, higher education, urban formal residence, and the African population group were associated with high HIV mass communication exposure (see Table 3).

4.3. Association between HIV Mass Communication Programmes and HIV Risk Behaviour. In multivariate analysis, greater exposure to HIV mass communication programmes was associated with greater HIV knowledge, condom use at last sex, having been tested for HIV in the past 12 months, and less stigmatizing attitude toward PLWHA (see Table 4). 


\section{Discussion}

Overall the study found that there was high exposure to the 18 different HIV communication programmes among the general population, especially among youth. Higher HIV mass communication exposure was in this study associated with improved HIV knowledge and lowered HIV/AIDS stigma, as found in previous studies [3-5, 12-15]. Further, higher HIV mass communication exposure was in this study, in agreement with other studies, associated with the reduction of HIV risk behaviour (e.g., condom use at last sex $[6,11,15-19]$ and having had an HIV test in the past 12 months) [20-23]. The study did not find any association between higher HIV mass communication exposure and reduction of the number of sexual partners, as found in some other studies $[18,24,25]$. Trend data from populationbased surveys in South Africa seem to confirm an increase in condom use, in particular among young people, but not a reduction in the number of sexual partners. Overall, the current study adds to the growing literature suggesting that mass media campaigns can be effective in changing HIV risk behaviour and attitudes, at least over the short term $[2,19]$. This finding confirms the development of a shift in the purpose of campaigns, from simply aiming to raise awareness about HIV and AIDS to attempting to impact safer sexual behaviours [2].

\section{Study Limitations}

The study design used was a weak (i.e., preexperimental) outcome evaluation design; more rigorous quasi-experimental designs are needed [2] including multiple assessments [19]. Exposure to communication campaigns relied on selfreporting, and it was not possible to measure the intensity of exposure, which should be included in further studies. The communication campaigns were not the only potential exposure to HIV and AIDS information among respondents, and direct and exclusive contributions to change cannot therefore be claimed. Further, the study found a low reliability of the HIV/AIDS stigma index used; therefore, if the stigma scale had been used as a scale, there would have been some limitation in validity of results. Finally, there are several biomedical and structural issues which the mass media could well have been instrumental for; their utilization in sub-Saharan Africa seems to be limited to behavioural interventions [26].

\section{Conclusions}

Exposure to communication campaigns in South Africa is associated with a range of outcomes relevant to addressing HIV and AIDS in relation to attitudinal aspects of the disease-particularly stigma reduction-and for HIV prevention. Communication campaigns thus provide a broad backdrop of support to HIV prevention activities and are likely to be strengthened via coherent and systematic prevention activities conducted at the community level.

\section{Acknowledgment}

This research has been supported by the President's Emergency Plan for AIDS Relief (PEPFAR) through the Centers for Disease Control and Prevention (CDC) under the terms of Cooperative Agreement number U2G/PS000570.

\section{References}

[1] J. T. Bertrand, K. O’Reilly, J. Denison, R. Anhang, and M. Sweat, "Systematic review of the effectiveness of mass communication programs to change HIV/AIDS-related behaviors in developing countries," Health Education Research, vol. 21, no. 4, pp. 567-597, 2006.

[2] S. M. Noar, P. Palmgreen, M. Chabot, N. Dobransky, and R. S. Zimmerman, "A 10-year systematic review of HIV/AIDS mass communication campaigns: have we made progress?" Journal of Health Communication, vol. 14, no. 1, pp. 15-42, 2009.

[3] L. Li, M. J. Rotheram-Borus, Y. Lu, Z. Wu, C. Lin, and J. Guan, "Mass media and HIV/AIDS in China," Journal of Health Communication, vol. 14, no. 5, pp. 424-438, 2009.

[4] S. Babalola, A. Fatusi, and J. Anyanti, "Media saturation, communication exposure and HIV stigma in Nigeria," Social Science and Medicine, vol. 68, no. 8, pp. 1513-1520, 2009.

[5] A. H. Creel, R. N. Rimal, G. Mkandawire, K. Böse, and J. W. Brown, "Effects of a mass media intervention on HIV-related stigma: "Radio Diaries" program in Malawi," Health Education Research, vol. 26, no. 3, pp. 456-465, 2011.

[6] S. Johnson, L. Kincaid, S. Laurence, F. Chikwava, R. Delate, and L. Mahlasela, Second National HIV Communication Survey 2009, JHHESA, Pretoria, South Africa, 2010.

[7] D. L. Kincaid and W. Parker, National AIDS Communication Programmes, HIV Prevention Behaviour, and HIV Infections Averted in South Africa, 2005, JHHESA, Pretoria, South Africa, 2008.

[8] O. Shisana, T. Rehle, L. C. Simbayi et al., South African National HIV Prevalence, Incidence, Behaviour and Communitcation Survey, 2008, HSRC Press, Cape Town, South Africa, 2009.

[9] M. Do, L. D. Kincaid, and M. E Figueroa, "The joint effects of 11 communication programs on HIV testing in South Africa: an application of multiple causal attribution analysis. Poster Presentation," in Proceedings of the 19th International AIDS Conference, Washington, DC, USA, July 2012.

[10] S. Goldstein, S. Usdin, E. Scheepers, and G. Japhet, "Communicating HIV and AIDS, what works? a report on the impact evaluation of Soul City's fourth series," Journal of Health Communication, vol. 10, no. 5, pp. 465-483, 2005.

[11] A. E. Pettifor, C. MacPhail, S. Bertozzi, and H. V. Rees, "Challenge of evaluating a national HIV prevention programme: the case of loveLife, South Africa," Sexually Transmitted Infections, vol. 83, supplement 1, pp. i70-i74, 2007.

[12] P. L. Hutchinson, X. Mahlalela, and J. Yukich, "Mass media, stigma, and disclosure of HIV test results: multilevel analysis in the Eastern Cape, South Africa," AIDS Education and Prevention, vol. 19, no. 6, pp. 489-510, 2007.

[13] K. Peltzer and S. Promtussananon, "Evaluation of soul city school and mass media life skills education among junior secondary school learners in south africa," Social Behavior and Personality, vol. 31, no. 8, pp. 825-834, 2003.

[14] J. Keating, D. Meekers, and A. Adewuyi, "Assessing effects of a media campaign on HIV/AIDS awareness and prevention in 
Nigeria: results from the VISION Project," BMC Public Health, vol. 6, article 123, 2006.

[15] S. Xiaoming, W. Yong, K. H. Choi, P. Lurie, and J. Mandel, "Integrating HIV prevention education into existing family planning services: results of a controlled trial of a communitylevel intervention for young adults in rural China," AIDS and Behavior, vol. 4, no. 1, pp. 103-110, 2000.

[16] C. Underwood, H. Hachonda, E. Serlemitsos, and U. BharathKumar, "Reducing the risk of HIV transmission among adolescents in Zambia: psychosocial and behavioral correlates of viewing a risk-reduction media campaign," Journal of Adolescent Health, vol. 38, no. 1, p. 55, 2006.

[17] M. W. Ross, N. S. Chatterjee, and L. Leonard, "A community level syphilis prevention programme: outcome data from a controlled trial," Sexually Transmitted Infections, vol. 80, no. 2, pp. 100-104, 2004.

[18] P. W. Vaughan, E. M. Rogers, A. Singhal, and R. M. Swalehe, "Entertainment-education and HIV/AIDS prevention: a field experiment in Tanzania," Journal of Health Communication, vol. 5, supplement, pp. 81-100, 2000.

[19] R. S. Zimmerman, P. M. Palmgreen, S. M. Noar, M. L. A. Lustria, H. Y. Lu, and M. L. Horosewski, "Effects of a televised two-city safer sex mass media campaign targeting high-sensation-seeking and impulsive-decision-making young adults," Health Education and Behavior, vol. 34, no. 5, pp. 810-826, 2007.

[20] K. Peltzer and P. Seoka, "Evaluation of HIV/AIDS prevention intervention messages on a rural sample of South African youth's knowledge, attitudes, beliefs and behaviours over a period of 15 months," Journal of Child and Adolescent Mental Health, vol. 16, no. 2, pp. 103-112, 2004.

[21] A. McOwan, Y. Gilleece, L. Chislett, and S. Mandalia, "Can targeted HIV testing campaigns alter health-seeking behaviour?" AIDS Care, vol. 14, no. 3, pp. 385-390, 2002.

[22] J. Vidanapathirana, M. J. Abramson, A. Forbes, and C. Fairley, "Mass media interventions for promoting HIV testing," The Cochrane Database of Systematic Reviews, no. 3, article CD004775, 2005.

[23] E. Marum, G. Morgan, A. Hightower, C. Ngare, and M. Taegtmeyer, "Using mass media campaigns to promote voluntary counseling and HIV-testing services in Kenya," AIDS, vol. 22, no. 15, pp. 2019-2024, 2008.

[24] Y. M. Kim, A. Kols, R. Nyakauru, C. Marangwanda, and P. Chibatamoto, "Promoting sexual responsibility among young people in Zimbabwe," International Family Planning Perspectives, vol. 27, no. 1, pp. 11-19, 2001.

[25] J. M. Kraft, Z. Hill, and I. Membe, "Effects of the Gama Cuulu radio serial drama on HIV-related behavior change in Zambia," Journal of Health Communication, vol. 17, no. 8, pp. 929-45, 2012.

[26] M. A. Bekalu and S. Eggermont, "Advancing HIV/AIDS Combination Prevention through mass media: a review of practices in sub-Saharan Africa," Information Development, vol. 28, no. 3, pp. 189-198, 2012. 


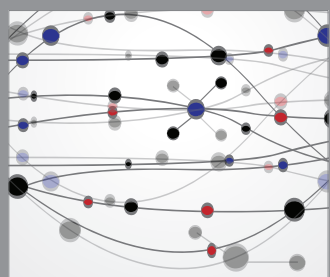

The Scientific World Journal
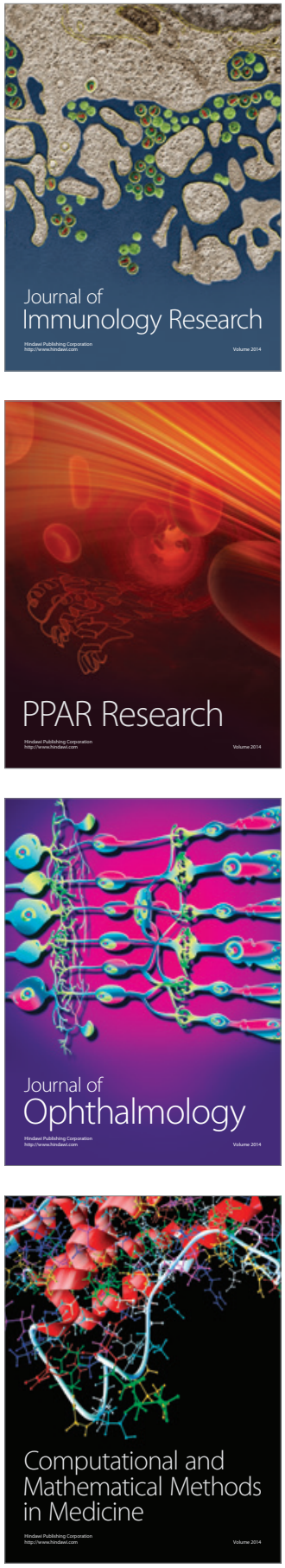

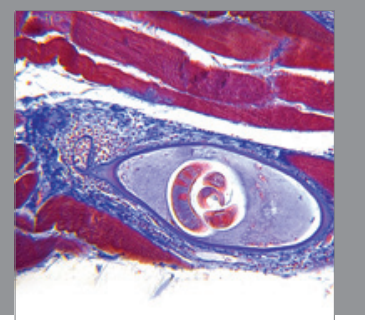

Gastroenterology

Research and Practice
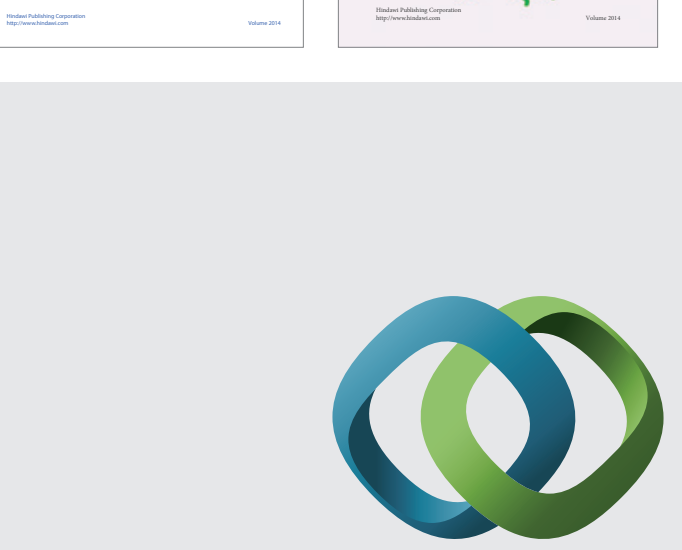

\section{Hindawi}

Submit your manuscripts at

http://www.hindawi.com
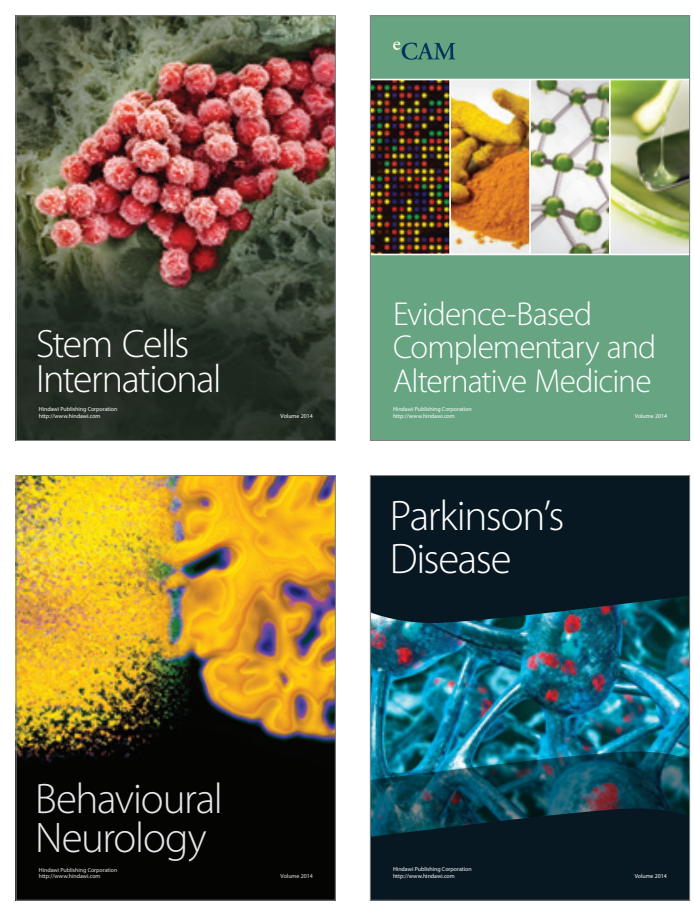

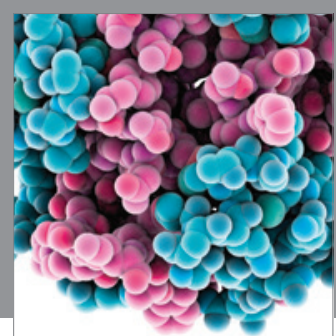

Journal of
Diabetes Research

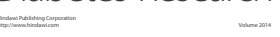

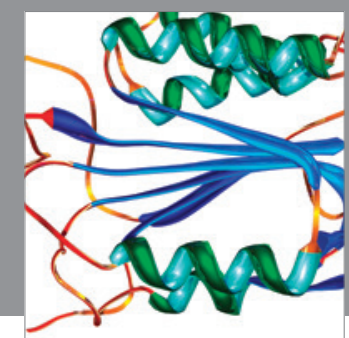

Disease Markers
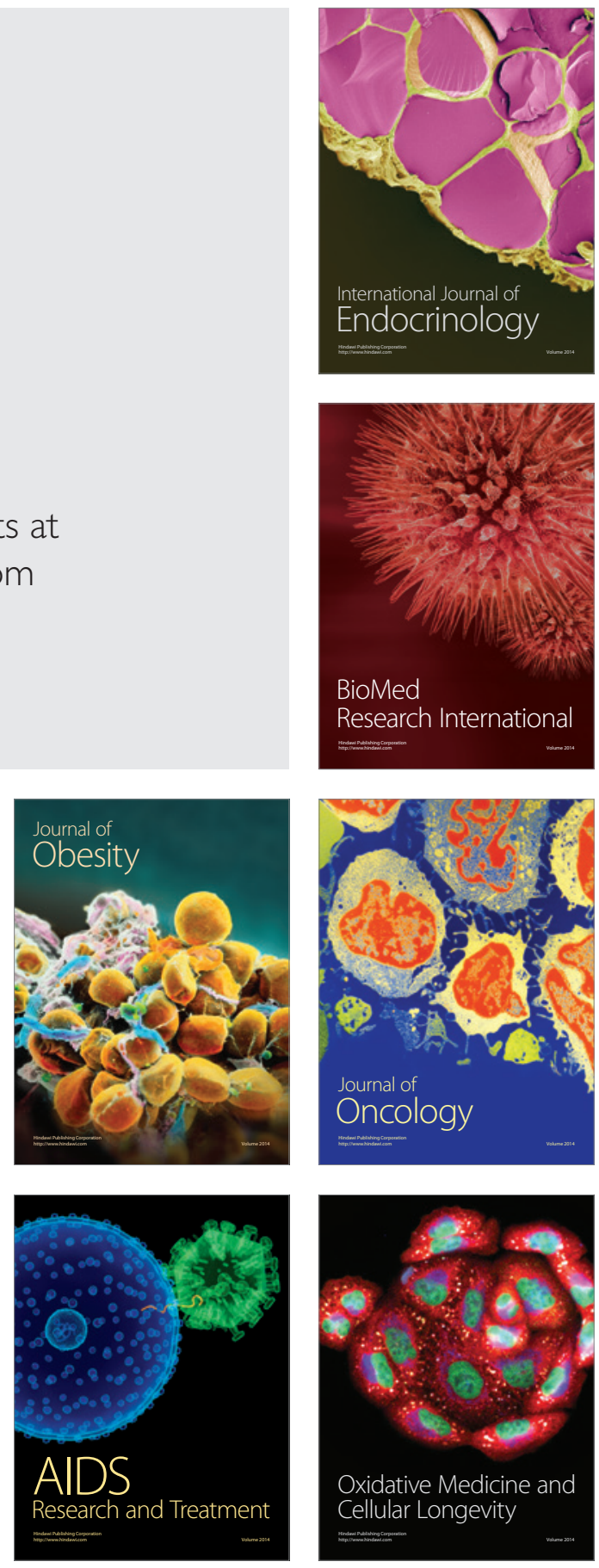